\title{
Controlling residual stress and distortion of friction stir welding joint by external stationary shoulder
}

https://doi.org/10.1515/htmp-2019-0005

Received Aug 06, 2018; accepted Dec 20, 2018

Abstract: Friction stir welding (FSW) can achieve a sound welding joint, but its residual stress and distortion cannot be avoided due to the non-uniformity of temperature distribution during welding. Stationary shoulder friction stir welding (SSFSW) was employed to butt weld 6005AT6 aluminum alloy plates. The effects of welding speeds ranging from $200 \mathrm{~mm} / \mathrm{min}$ to $600 \mathrm{~mm} / \mathrm{min}$ on residual stress and distortion were investigated in detail. A thermomechanical model was utilized to compare the residual stress distribution between conventional FSW and SSFSW. SSFSW was beneficial to decreasing the peak temperature of stir zone (SZ) and then obtaining a narrower SZ. The peak residual stress produced by SSFSW was 50\% lower than that by conventional FSW and a narrower tensile stress region was attained by SSFSW. Moreover, the stationary shoulder applied a function of synchronous rolling during the welding, which controlled the distortion effectively.

Keywords: Friction stir welding, stationary shoulder, residual stress, synchronous rolling, distortion

\section{Introduction}

Friction stir welding (FSW) technology was invented by Wayne Thomas at TWI in 1991 [1]. As a newly emerged solid-state joining technology, FSW has been rapidly developed [2]. Huang et al. [3] revealed that frictional heat

\footnotetext{
*Corresponding Author: Wei Hu: Faculty of Aerospace Engineering, Shenyang Aerospace University, Shenyang 110136, P. R.China; Email: huwei201805@126.com

Weiliang He, Jinglin Liu, Gongdong Wang: Faculty of Aerospace Engineering, Shenyang Aerospace University, Shenyang 110136, P. R.China

Wenjing Chen: Sailun Jinyu Group Co., Ltd, Qingdao 266000, P. R.China

Weiliang He and Jinglin Liu contributed equally to this work
}

was generated by rotating tool through extrusion and stirring during FSW. Threadgill et al. [4] reported that the frictional heat induced by the rotating shoulder reached $70 \%-$ $80 \%$ of the total heat input. During FSW, the thermal expansion of weld is inhibited by the adjacent cold materials, thereby inevitably producing the welding residual stress in the welded plate $[5,6]$. The residual stress has been intensively investigated in recent years. Aval et al. [7] and Kang et al. [8] reported that a relatively high longitudinal tensile stress appeared near the rotating shoulder edge. Richards et al. [9] and Altenkirch et al. [10] reported that the welding residual stress presented an ' $M$ ' shape along the direction perpendicular to the weld, and its peak value was located at the transition region between heat affected zone (HAZ) and stir zone (SZ). Riahi et al. [11] and Steuwer et al. [12] investigated that the peak residual stress on the upper surface of butt joint decreased with a decrease in welding speed. However, welding residual stress is an important factor which directly affects the mechanical properties of welding joint, such as yield strength and fatigue strength [13, 14]. Therefore, the burning question about how to reduce the welding residual stress to improve the mechanical properties has been attracting more and more attentions.

Stationary shoulder FSW (SSFSW) is a variant of the conventional FSW technique, and its tool system consists of an interior rotating tool and an external stationary shoulder [15]. The SSFSW is a latecomer in the welding techniques and was initially invented to weld titanium alloy to overcome uneven temperature distribution along the joint thickness [16]. Avettand et al. [17] demonstrated that the external stationary shoulder absorbed a large quantity of frictional heat, thereby resulting in a relatively narrow and uniform through-thickness temperature field. Li et al. [18] indicated that SSFSW was developed to improve the asymmetry and inhomogeneity of microstructure in aluminum alloy joint. Liu et al. [19] reported that for the joints of 2219-T6 alloy, the relatively symmetrical thermo-mechanically affected zone (TMAZ) and HAZ could be obtained by SSFSW. So far, the investigations on SSFSW have mainly focused on microstructure

ə Open Access. (c) 2019 W. He et al., published by De Gruyter. (Cc) BY This work is licensed under the Creative Commons Attribution 4.0 License 
Table 1: Chemical compositions and mechanical properties of 6005A-T6 aluminum alloy

\begin{tabular}{|c|c|c|c|c|c|c|c|c|c|}
\hline \multicolumn{8}{|c|}{ Chemical compositions (mass \%) } & \multicolumn{2}{|c|}{ Mechanical properties } \\
\hline $\mathrm{Si}$ & $\mathrm{Fe}$ & $\mathrm{Cu}$ & $M n$ & $\mathrm{Mg}$ & $\mathrm{Zn}$ & $\mathrm{Cr}$ & $\mathrm{Al}$ & Yield strength (MPa) & Elongation (\%) \\
\hline 0.6 & 0.35 & 0.30 & 0.50 & 0.50 & 0.20 & 0.30 & Balance & 145.5 & 9.7 \\
\hline
\end{tabular}
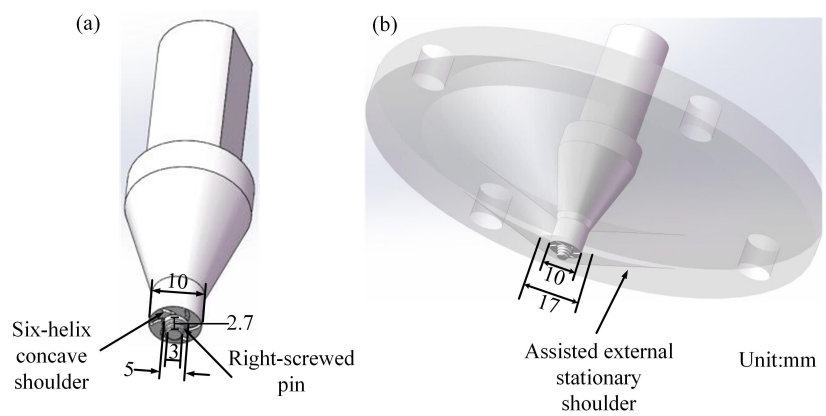

Figure 1: Schematics of (a) conventional tool and (b) stationary shoulder tool systems

and mechanical properties of welding joint, and few literatures about the welding stress and distortion of SSFSW joint have been reported [20, 21].

Welding is a complex process with the coupled thermal and mechanical behaviors, which is difficult for experimental result to understand the evolution of welding stress. The finite element simulation has been verified to solve this above problem. A major thrust of current research focused on employing the ABAQUS software to analyze the temperature and stress field during SSFSW. Furthermore, the controlling effect of residual stress produced by the external stationary shoulder has been discussed.

\section{Experimental procedures}

In this study, 6005A-T6 aluminum alloy was selected as a target material due to its excellent extrusion formability and good weldability [22]. Table 1 lists the chemical compositions and mechanical properties of 6005A-T6 aluminum alloy. In comparison with conventional concentric-circlesflute shoulder, a three-spiral-flute shoulder can accelerate the material flow rate [23]. On this basis, a six-spiral-flute shoulder was designed. The tools used in the conventional FSW and SSFSW technologies are illustrated in Figure 1. The stationary shoulder system consisted of an interior rotating tool and an external stationary shoulder, and this rotating tool possessed the same geometries as those of tool used in the conventional FSW process. The welding process was conducted on an FSW machine and the tilting angle of the tool was $2.5^{\circ}$. Prior to welding, the surfaces of

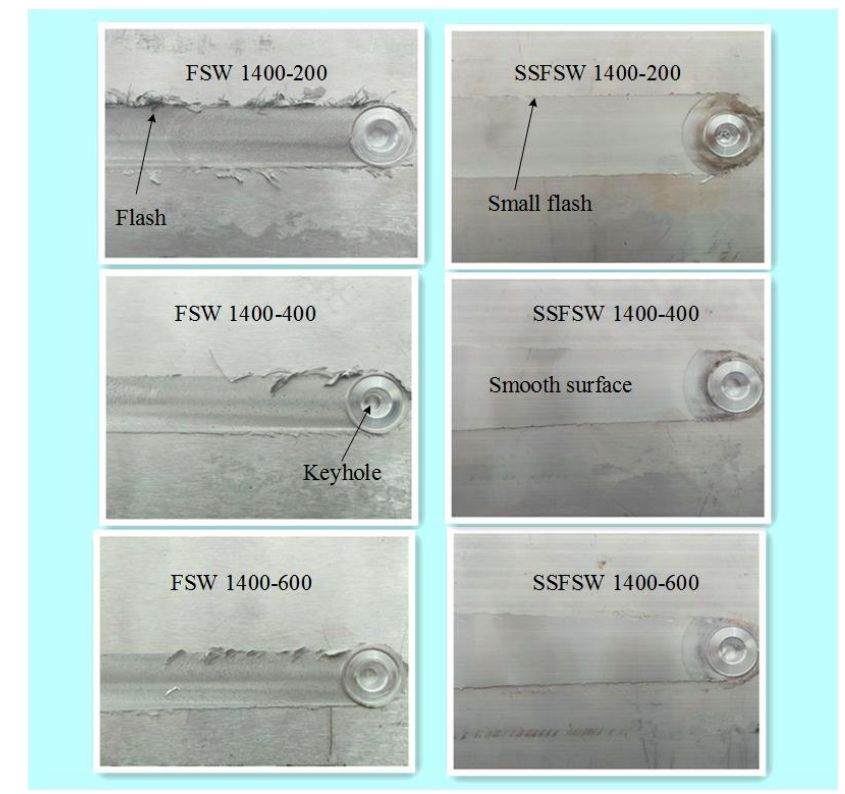

Figure 2: Surface appearances of conventional FSW and SSFSW joints

all plates were cleaned with emery papers to remove oxidation layers.

The welding parameter combination is an important factor which directly affects the distribution of temperature and residual stress. Li et al. [24] found that the ratio of rotating speed to welding speed $(n / v)$ greatly influenced the quality of FSW joint, and the distortion of the joint becomes more obvious with increasing the $n / v$. In fact, controlling the welding stress and distortion should be based on the premise of the high mechanical properties of welding joint which is greatly influenced by the $n / v$. According to the literature reported by Meng et al. [25], the sound 6005A-T6 alloy FSW joint can be attained when the $n / v$ varies from 3.3 to 20 , and the tensile properties of joint can reach a maximum value at approximately 5 . Therefore, the rational ratios were selected and are given in Table 2. In this study, the rotating speed of $1400 \mathrm{rpm}$ was constant, and the welding speeds were 200, 400 and 600 $\mathrm{mm} / \mathrm{min}$, respectively. The experimental results of joint surfaces are displayed in Figure 2, and the good surfaces without tunnel defect partly verify the rationality of welding parameters. The K-type thermocouples were used to measure the temperature during welding, which were lo- 
Table 2: The matrix of conventional FSW and (SSFSW) welding parameters

\begin{tabular}{ccccc}
\hline $\begin{array}{c}\text { Trial } \\
\text { no. }\end{array}$ & Designation & $\begin{array}{c}\text { Welding } \\
\text { speed } \\
\mathrm{mm} / \mathrm{min}(v)\end{array}$ & $\begin{array}{c}\text { Rotating } \\
\text { speed } \\
\mathrm{rpm}(n)\end{array}$ & $n / v$ \\
\hline 1 & $\mathrm{~F} 1400 / 200$ & 200 & 1400 & 7 \\
2 & $\mathrm{~F} 1400 / 400$ & 400 & & 3.5 \\
3 & $\mathrm{~F} 1400 / 600$ & 600 & 2.3 \\
4 & SS1400/200 & 200 & 7 \\
5 & SS1400/400 & 400 & 3.5 \\
6 & SS1400/600 & 600 & & 2.3 \\
\hline
\end{tabular}

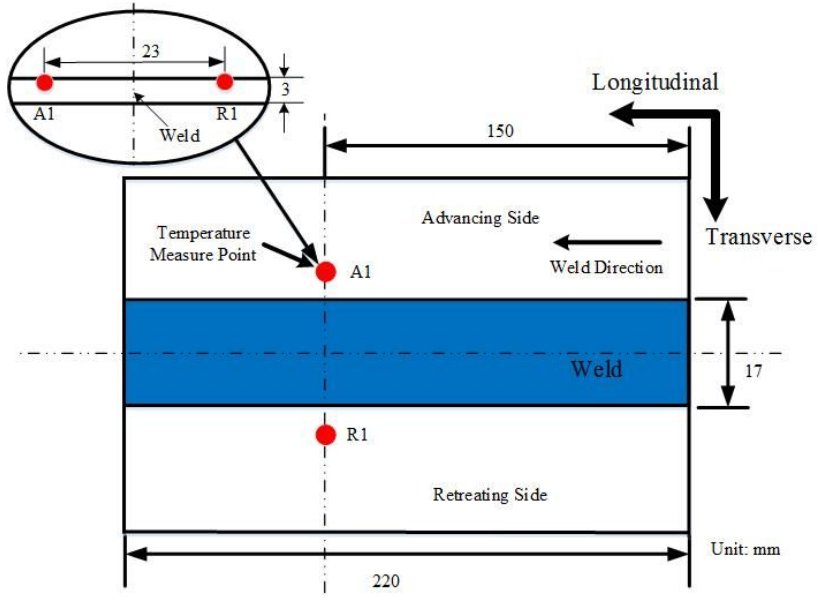

Figure 3: Partial magnified diagram of the temperature measurement points

cated outside the SZ in order to avoid the damage of thermocouples induced by the rotating tool. Moreover, it is difficult for the thermocouples to attain a whole temperature evolution curve during welding, when the thermocouples are located in the SZ [26]. The positions of the Ktype thermocouples are shown in Figure 3. Prior to welding, the thermocouples with $0.5 \mathrm{~mm}$ diameter were inserted into the holes at the advancing side (AS) and retreating side (RS) of the plate to be welded. The longitudinal residual stresses were measured by ultrasonic method after the welding. The distortions were measured by a threecoordinate-measuring machine (CMM). The displacement sensor scanned through the plate and the locations of sensor were recorded in different directions. In addition, the specimens for metallographic macrostructure were cut perpendicular to the welding direction by using an electrical discharge cutting machine. The metallographic specimens were etched with Keller's reagent, and the macrographs of the joint cross-sections were observed using optical microscopy (OM).

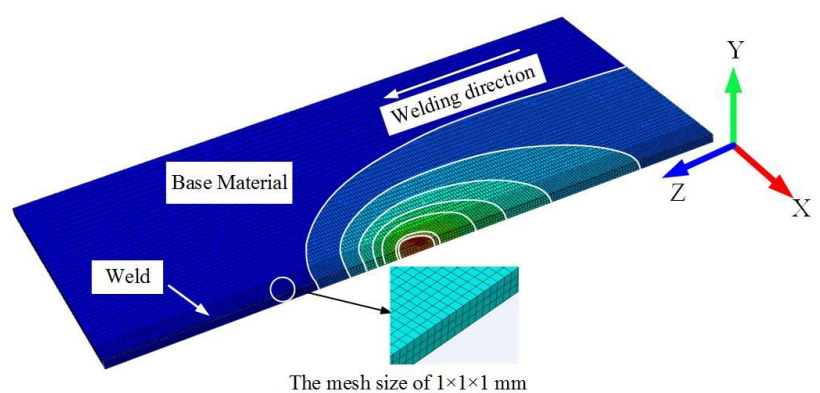

Figure 4: Example of FE model mesh

\section{Finite element modelling}

The model was established in accordance with the plate size of $220 \mathrm{~mm} \times 110 \mathrm{~mm} \times 3 \mathrm{~mm}$ through the ABAQUS finite element software. Thermal and physical properties which changes with temperature are exhibited in Table 3. The mesh size around weld in Figure 4 was set as $1 \mathrm{~mm}$ to improve the accuracy calculation, while the larger mesh size was selected far away from the weld to reduce the calculation expense. The contact heat conductivity between the welded plate and the backing plate was $120 \mathrm{~W} /\left(\mathrm{m}^{2} \cdot{ }^{\circ} \mathrm{C}\right)$ and the heat convection coefficient was $40 \mathrm{~W} /\left(\mathrm{m}^{2} \cdot{ }^{\circ} \mathrm{C}\right)$. In addition, a downward pressure of $7500 \mathrm{~N}$ between the external stationary shoulder and the welded plated was applied to the weld by surface load. The contact heat conductivity between the welded plate and the shoulder were set to be $35 \mathrm{~W} /\left(\mathrm{m}^{2} \cdot{ }^{\circ} \mathrm{C}\right)$.

Based on Zhang et al. [26], the frictional heat between the rotating shoulder and the workpiece surface can be expressed as:

$$
Q_{s}=\int_{r_{o}}^{R_{o}} 2 \pi \mu w p(T) \cdot r^{2} d r=\frac{2}{3} \pi \mu w p(T) \cdot\left(R_{o}^{3}-r_{o}^{3}\right)
$$

where $Q_{s}$ is the thermal input generated by friction between the rotating shoulder and the welded plate, $w$ is the angular velocity, $R_{o}$ is the rotating shoulder radius, $r_{o}$ is the rotating pin radius, $P$ is the stress when plastic strain of $0.2 \%$ is produced and $\mu$ is the frictional coefficient. The frictional heat caused by the pin was $25 \%$ of that by the rotating shoulder [27]. The heat produced by the pin $\left(Q_{p}\right)$ is given by:

$$
Q_{p}=0.25 \cdot Q_{s}
$$


Table 3: The temperature-dependent material properties of 6005A-T6

\begin{tabular}{cccccc}
\hline $\begin{array}{c}\text { Temp. } \\
{\left[{ }^{\circ} \mathrm{C}\right]}\end{array}$ & $\begin{array}{c}\text { Conductivity } \\
{\left[\mathrm{W} / \mathrm{m} \cdot{ }^{\circ} \mathrm{C}\right]}\end{array}$ & $\begin{array}{c}\text { Specific Heat } \\
{\left[\mathrm{J} / \mathrm{kg} \cdot{ }^{\circ} \mathrm{C}\right]}\end{array}$ & Yield Stress $[\mathrm{MPa}]$ & Expansion $\left[/{ }^{\circ} \mathrm{C}\right]$ & $\begin{array}{c}\text { Young's Modulus } \\
{[\mathrm{GPa}]}\end{array}$ \\
\hline 20 & 202.4 & 919 & 201 & $2.28 \mathrm{E}-005$ & 68 \\
50 & 206.3 & 922.5 & 200 & $2.31 \mathrm{E}-005$ & 65 \\
100 & 207.5 & 925 & 175 & $2.48 \mathrm{E}-005$ & 62 \\
150 & 211.5 & 950 & 125 & $2.57 \mathrm{E}-005$ & 58 \\
200 & 210 & 975.5 & 50 & $2.65 \mathrm{E}-005$ & 55.5 \\
250 & 212.5 & 980 & 25 & $2.73 \mathrm{E}-005$ & 52 \\
300 & 208 & 1010 & 24 & $2.79 \mathrm{E}-005$ & 44 \\
350 & 205 & 1025 & 22 & $2.82 \mathrm{E}-005$ & 42 \\
400 & 202.5 & 1089 & 21 & $2.87 \mathrm{E}-005$ & 40 \\
\hline
\end{tabular}
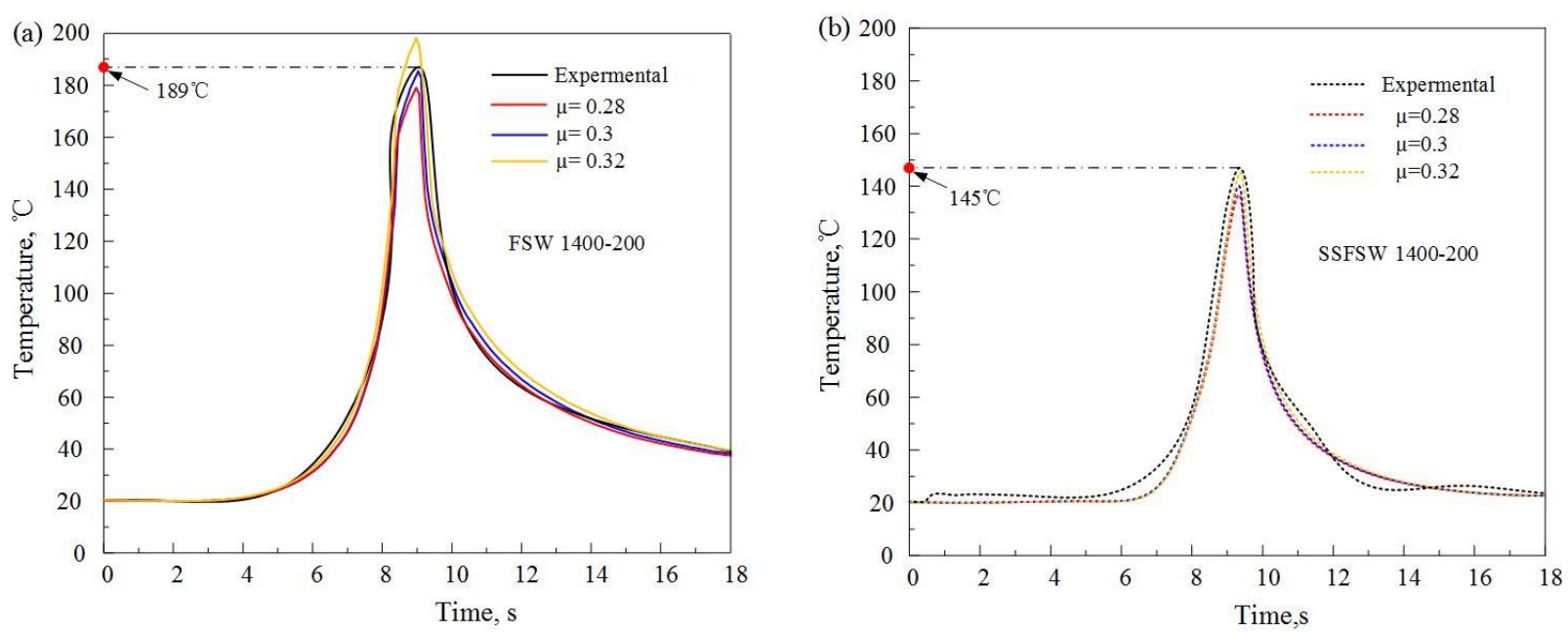

Figure 5: Comparisons of temperature history curves between experimental and numerical results: (a) conventional FSW and (b) SSFSW

\section{Results and discussion}

\subsection{Heat source verification}

The selection of the frictional coefficient is much more predominant for the current model. In this study, $R_{0}, r_{0}$ and $\omega$ in Eq. 1 are $5 \mathrm{~mm}, 2 \mathrm{~mm}, 1400 \mathrm{rpm}$, respectively. Three different frictional coefficients $(\mu=0.28, \mu=0.3$ and $\mu=0.32$ ) were compared to obtain an optimized one to ensure the computational accuracy.

Taking the measurement temperature point on the AS, as an example, the temperature evolutions under three different frictional coefficients are shown in Figure 5. When using the conventional tool, the peak temperatures by simulation are $179.3^{\circ} \mathrm{C}$ (at $\mu=0.28$ ), $188.2^{\circ} \mathrm{C}$ (at $\mu=0.3$ ) and $198^{\circ} \mathrm{C}$ (at $\mu=0.32$ ). For the stationary shoulder tool system, the peak temperatures by simulation are $138.6^{\circ} \mathrm{C}$ (at $\mu=0.28$ ), $140^{\circ} \mathrm{C}$ (at $\mu=0.3$ ) and $143.2^{\circ} \mathrm{C}$ (at $\mu=0.32$ ). According to the error of temperature between numerical and experimental results in Figure 5, the frictional coefficients for FSW and SSFSW are chosen as 0.3 and 0.32, respectively. Therefore, the temperature field during welding can be accurately described by the verified finite element

\subsection{Temperature and stress fields during welding}

During the welding process, the maximum temperature generally locates at the weld and an observed point at the weld center was selected to investigate the temperature evolution. The thermal cycle curves under different welding conditions are summarized in Figure 6. The peak temperature by conventional FSW process ranges from $410^{\circ} \mathrm{C}$ to $450^{\circ} \mathrm{C}$, when the welding speed varies from $600 \mathrm{~mm} / \mathrm{min}$ to $200 \mathrm{~mm} / \mathrm{min}$. The melting point of 6005A-T6 aluminum alloy is $550^{\circ} \mathrm{C}$, and the peak temperature reaches $74.5 \%-81.8 \%$ of the material melting point. 


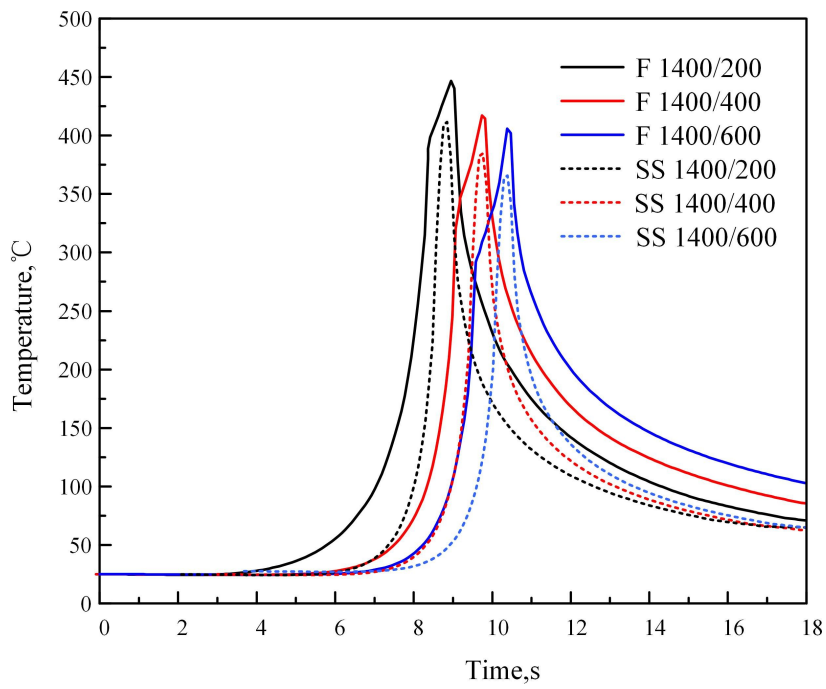

Figure 6: Temperature histories of weld center by simulation under different welding processes

The peak temperature decreases with the increase of the welding speed because the thermal input per unit length decreases. Moreover, the conventional FSW and the SSFSW possess the same temperature history trend, and the temperature of material heightens fast when the tool approaches the observed point at the heating stage and reduces rapidly when the tool moves away at the cooling stage. For the SSFSW process, the inner rotational tool is surrounded by the external stationary shoulder and this stationary shoulder contacting with the plate top surface can absorb the heat near the weld. Therefore, the temperature during SSFSW heightens more slowly and reduces more rapidly, and the temperature history curves by SSFSW have a narrower region with high temperature compared with those by conventional FSW. model.

To compare the temperature field along the plate thickness and further verify the rationality of FE model, the cross sections attained by simulation and experiment are plotted in Figure 7. No defects are observed in all the cross sections, which further verifies the reasonability of the selected welding speeds varying from $200 \mathrm{~mm} / \mathrm{min}$ to $600 \mathrm{~mm} / \mathrm{min}$. During the welding process, increasing the welding speed decreases the thermal input per unit length, thereby leading to the decreased material flow velocity in SZ [28]. Therefore, the SZ width decreases with the increase of welding speed. For conventional FSW process, the cross section of SZ presents a bowl-like shape (Figure 7a). For the SSFSW process, the cross section of SZ presents a morphology similar to the tool pin, as shown in Figure $7 \mathrm{~b}$. The difference of cross-sectional morphology between conventional FSW and SSFSW is mainly because the external stationary shoulder can absorb the heat of plate top surface. From Figures 6 and 7, it is known that the assisted external stationary shoulder not only reduces the peak temperature in the SZ but also shrinks the region with high temperature, which is beneficial to controlling the welding residual stress and distortion.

Figure 8 shows the temperature and longitudinal stress fields predicted by the simulation, and four different regions are marked in the maps. For the FSW, the frictional heat generated by the rotating tool diffuses to the surrounding material during welding, and the material in front of the tool experiences the heat conduction and produces the thermal expansion. This expanded material is restricted by the surrounding cold materials, so the compressive stress is produced at region 2 in Figure 8b [5]. Region 3 presents the region where the rotating tool shoulder contacts with the plate. For this region, the welding stress of $-2 \mathrm{MPa}$ is close to zero under the condition of large strain, which is mainly due to the very small elasticity modulus of material with high temperature. Region 4 far away from the welding heat source possesses the low temperature close to room temperature, where the large tensile stress appears because the shrinkage of material in the weld at the cooling stage is constrained by the surrounding materials on both sides of weld. As mentioned above, the external stationary shoulder can reduce the peak temperature in the SZ, which can reduce the tensile stress. In fact, this stationary shoulder also can play a role of synchronous rolling, which can further reduce the tensile stress at the cooling stage. Therefore, the tensile stress of region 4 by SSFSW is much lower than that of region 1 by conventional FSW, and the value decreases from $69 \mathrm{MPa}$ to $40 \mathrm{MPa}$.

\subsection{Welding residual stress and distortion}

The distributions of longitudinal residual stresses perpendicular to the weld produced by conventional FSW and SSFSW are displayed in Figure 9. An 'M' shaped stress distribution is clearly observed, and this similar distribution was reported in Ref. [29] on FSW of 6061-T6 aluminum alloy. Peel et al. [30] put forward that the "M" shaped stress distribution was induced by the non-uniform temperature field in the transverse section. The peak tensile residual stresses in Figure 9 are located at $\pm 5 \mathrm{~mm}$ or so from the weld line. According to the geometry of the welding tool, it is known that the peak tensile residual stress appears at the edge of rotating tool shoulder. This is related to the high temperature in the SZ and the high shear force between the shoulder edge and the welded plate during welding [31]. In order to keep balance with the tensile residual stress near the 
(a)
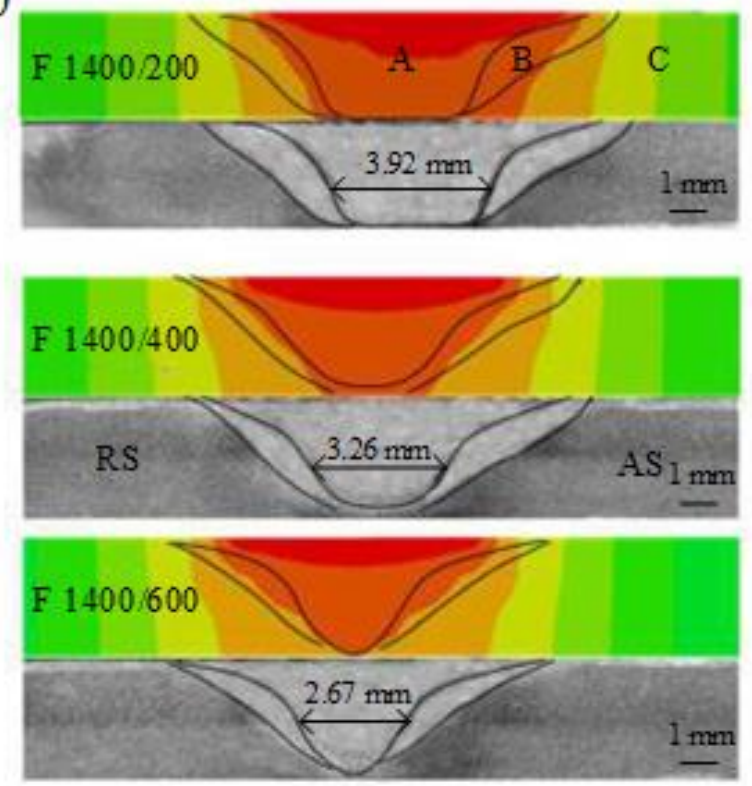

(b)
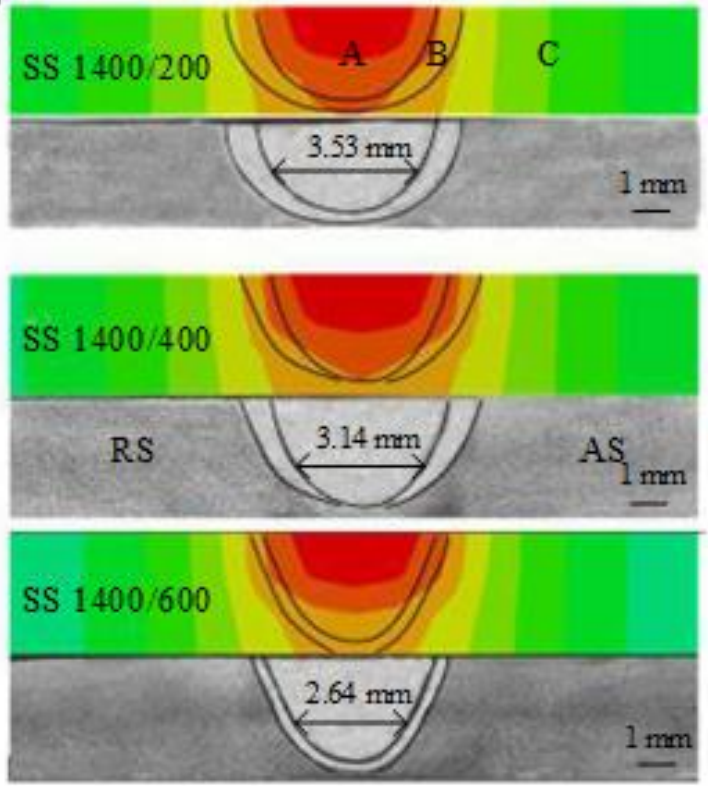

Figure 7: Temperature maps of cross-sections under different welding processes: (a) FSW and (b) SSFSW

weld, the compressive residual stress is produced in the region far away from the weld.

It is evident from Figure 9 that the tensile stress is asymmetric with respect to the welding center and the value on AS is about $10 \%$ higher than that on RS. This is partly because the relative motion between the rotating tool and the welded plate can produce an additional tensile stress on the materials in the weld and this relative speed on the AS is higher than that on the RS [32]. Meanwhile, the lower welding speed results in a lower tensile residual stress. At 200, 400 and $600 \mathrm{~mm} / \mathrm{min}$, the longitudinal residual stresses by conventional FSW are respectively 81, 102 and $118 \mathrm{MPa}$. Sun et al. [33] reported that the higher peak temperature during welding increased the tensile residual stress of welding joint. However, besides the peak temperature in the SZ, the temperature gradient and the cooling rate behind the rotating tool can greatly influences the tensile residual stress. Kang et al. [34] performed the investigation of 6061-T6 alloy FSW joint and stated that increasing the welding speed during welding heightened the tensile residual stress because the temperature gradient had a steep grade and an insufficient stress relief time under a higher welding speed. In this study, how the welding speed influences the residual stress (Figure 9) agrees with that in previous studies [34], rather than [33].

As mentioned above, the external stationary shoulder can absorb the frictional heat during welding, leading to the lower peak temperature in the SZ. Generally speaking, lower peak temperature is beneficial to reducing the weld- ing residual stress [35]. Moreover, compared with the conventional tool, the external stationary shoulder tool system can apply an extra vertical force on the weld top surface due to the addition of external stationary shoulder, resulting in an extra tensile strain in the weld. This extra tensile strain can offset the compressive plastic strain induced by the heat input during welding, leading to the decrease of tensile residual stress of welding joint. This effect on welding residual stress can be regarded as a 'in situ direct rolling' process (ISDR). Wen et al. [36] stated that the ISDR process gave a significant reduction in the longitudinal residual stress. In this study, the residual stress produced by SSFSW is much lower than that by the conventional FSW, which results from the above-mentioned two reasons. When the welding speeds of 200,400 and $600 \mathrm{~mm} / \mathrm{min}$ are used, the peak tensile residual stresses by SSFSW are reduced to 38.5, 52.1 and $78.9 \mathrm{MPa}$, respectively. Compared with the conventional FSW, the SSFSW process can reduce the tensile residual stress by approximately $50 \%$.

Figure 10 gives the distortions of the conventional FSW and SSFSW joints under different welding speeds. It can be seen that the welded plate presents a saddle shape distortion. Guo et al. [37] have investigated the effect of thermal input on welding distortion. They found that the longitudinal shrinkage in the weld zone was in direct proportion to the thermal input and the distortion was similar as a saddle. Shi et al. [38] pointed out that increasing the welding speed reduced the thermal input and subsequent peak 
Temperature field $\left({ }^{\circ} \mathrm{C}\right.$ )

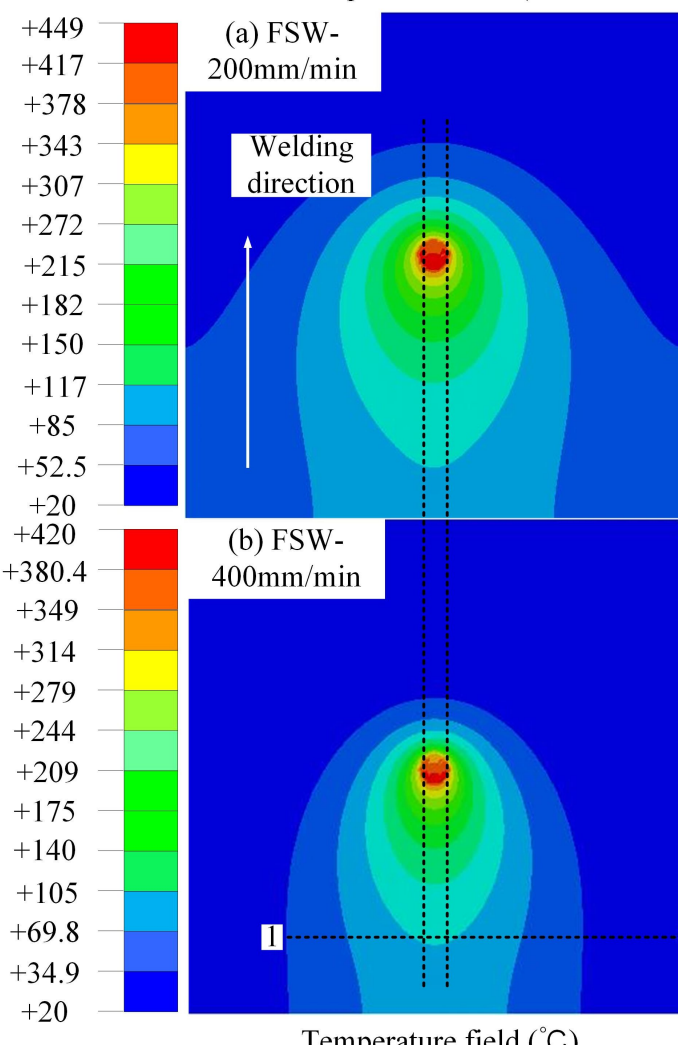

Temperature field $\left({ }^{\circ} \mathrm{C}\right)$

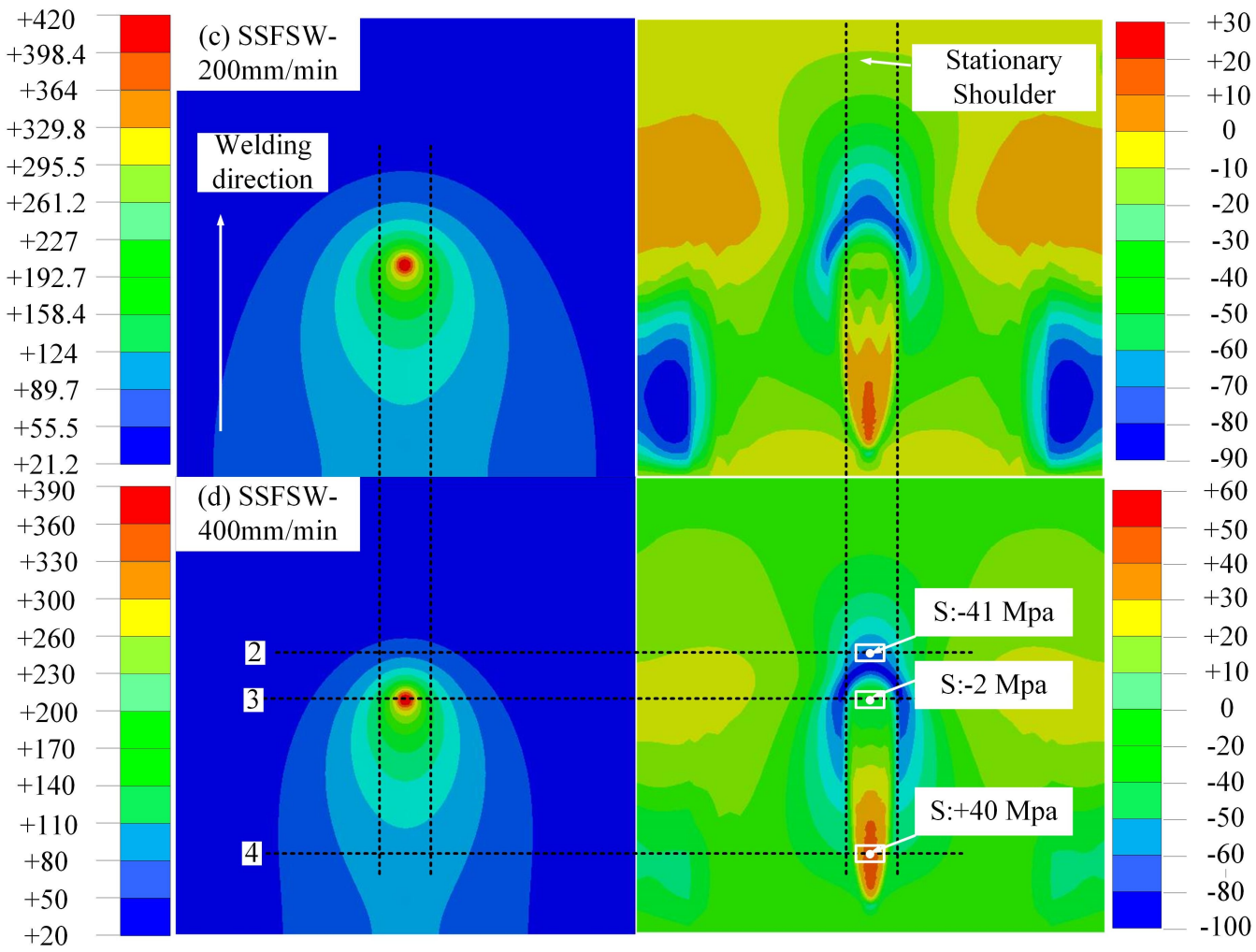

Stress field (MPa)

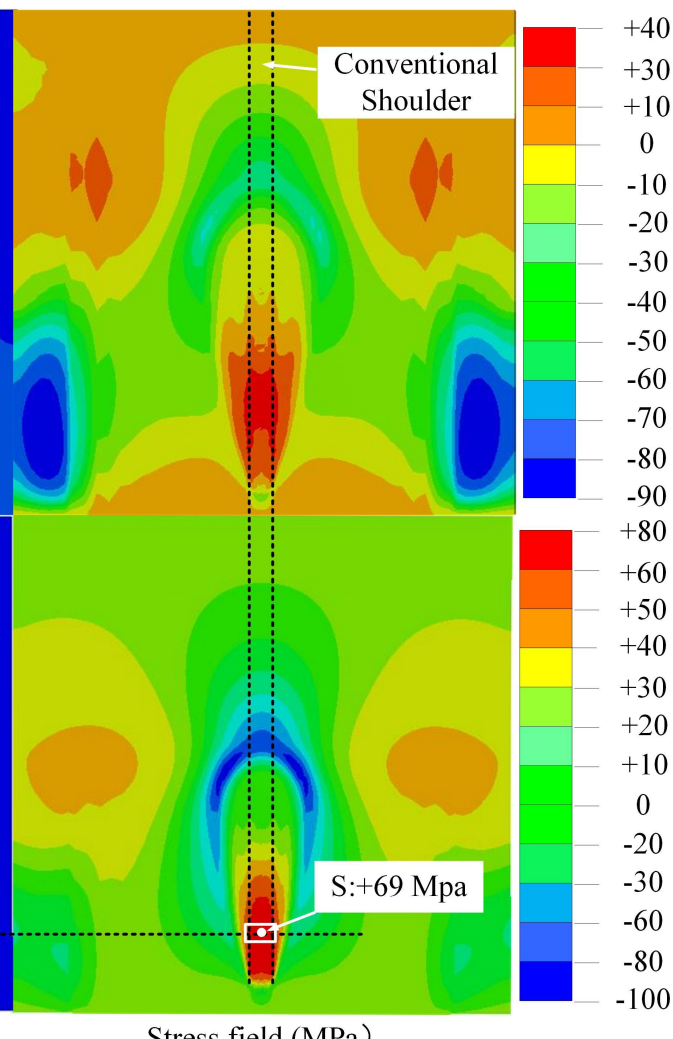

Stress field (MPa) 

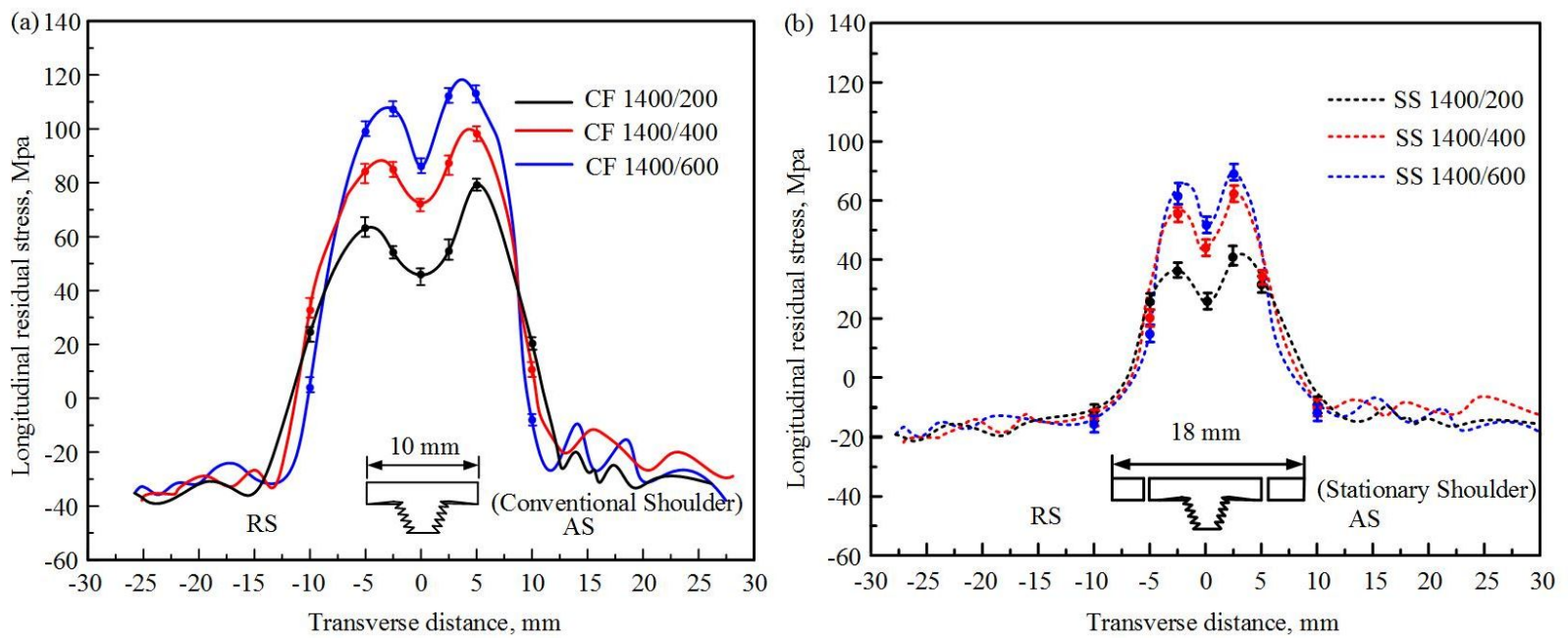

Figure 9: Longitudinal residual stress distributions perpendicular to the weld: (a) conventional FSW and (b) SSFSW

(a)

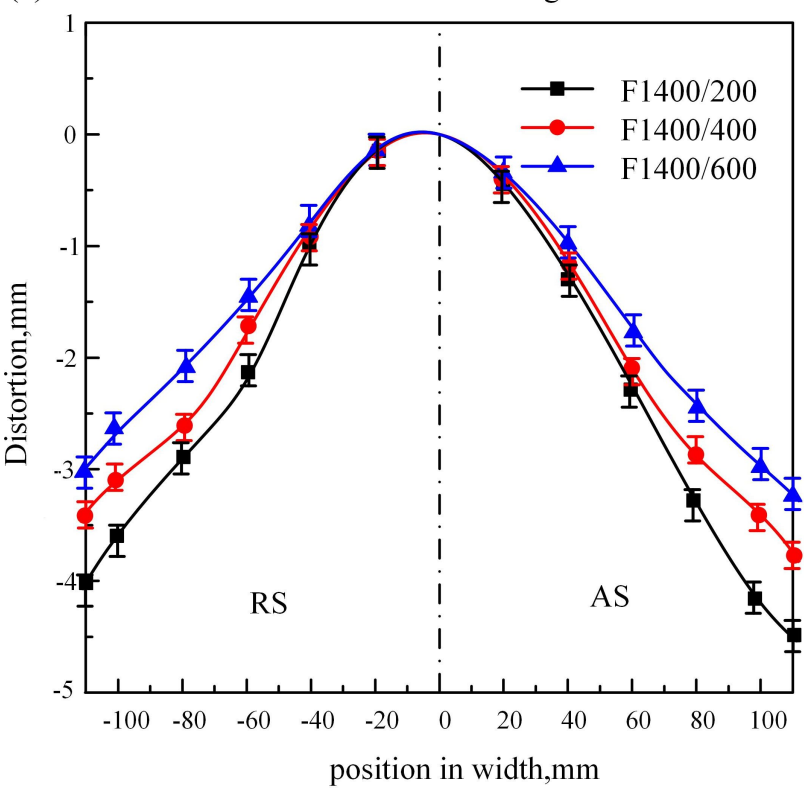

(c)

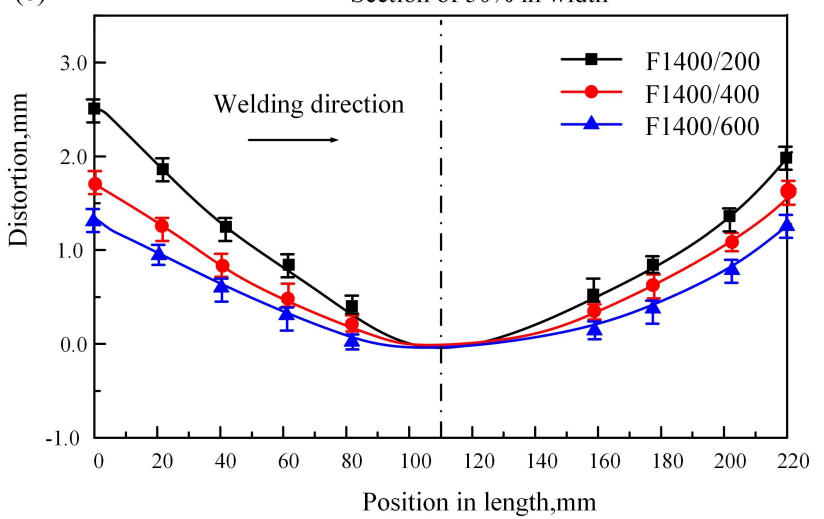

(b)

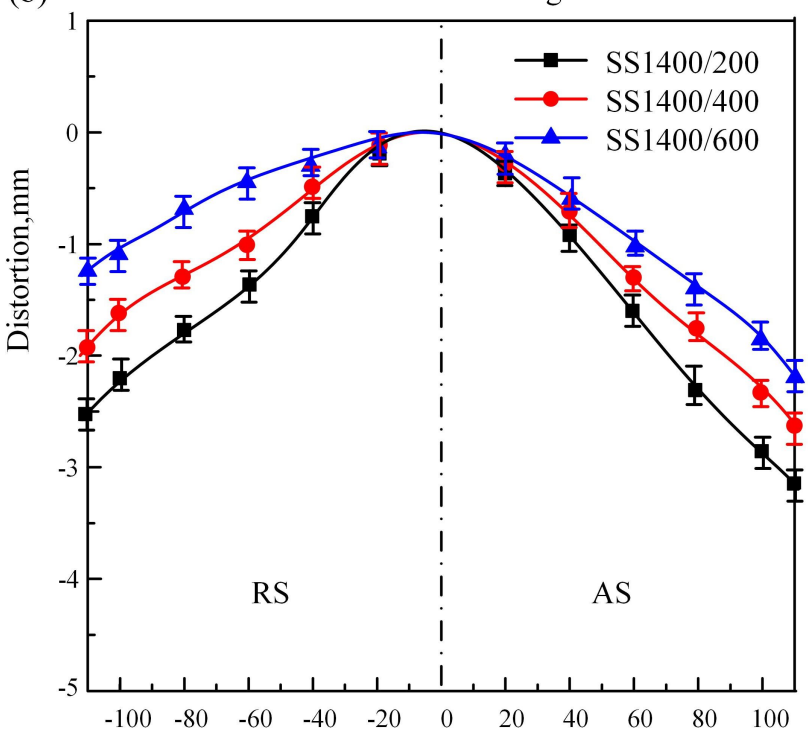

position in width, $\mathrm{mm}$

(d)

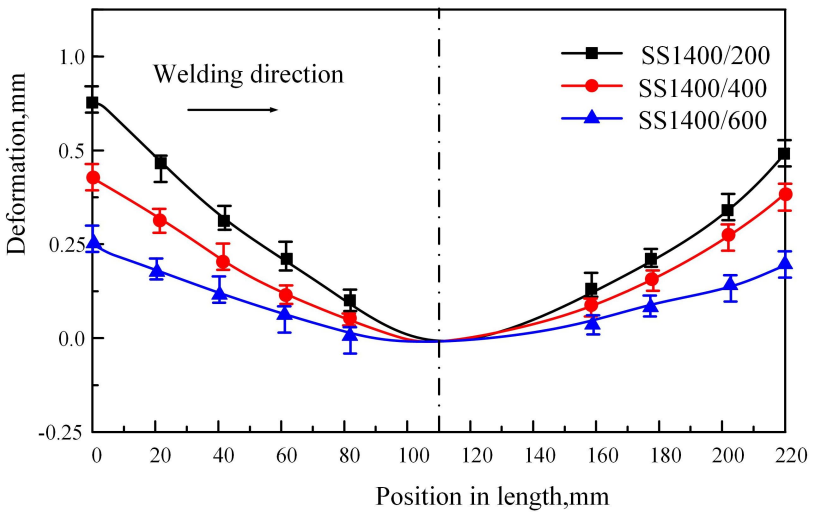

Figure 10: Distortion curves of joints in transverse sections and longitudinal sections under different welding processes: (a) and (c) conventional FSW; (b) and (d) SSFSW 
temperature during welding, leading to a smaller residual distortion. The experimental results in Figure 10 agree with the results in the above two literatures. When the welding speeds of 200, 400 and $600 \mathrm{~mm} / \mathrm{min}$ are used during conventional FSW, the maximum residual distortions in length are $2.5,1.7$ and $1.3 \mathrm{~mm}$ and these values in width are 4.5, 3.8 and $3.2 \mathrm{~mm}$, respectively. Moreover, the distortion produced by the SSFSW is much smaller than that by the conventional FSW at the same welding speed, which is due to the combined effect of lower peak temperature and the synchronous rolling induced by the addition of stationary shoulder.

\section{Conclusions}

The stationary shoulder was employed to reduce the welding residual stress and distortion of the welding joints. 6005A-T6 alloys was chosen as the research object and the comparisons between the conventional FSW and SSFSW joints were conducted in detail. The following conclusions can be drawn on the basis of the present study.

(1) The cross section of SZ during conventional FSW presents a bowl-like shape. With increasing the welding speed, the peak temperature of SZ is reduced and the width of SZ is shrunk.

(2) Compared with conventional FSW, the temperature by SSFSW is heightened more slowly at the heating stage and is reduced more rapidly at the cooling stage. The addition of stationary shoulder can reduce the peak temperature in the SZ and shrink the region with high temperature.

(3) The welding residual stress increases with increasing the welding speed and the value on the RS is lower than that on the AS. The maximum residual stress produced by the SSFSW is approximately $50 \%$ lower than that by the conventional FSW.

(4) The welded plate presents a saddle-shaped distortion and the distortion decreases with the increase of welding speed. An additional external stationary shoulder plays a synchronous rolling role during welding, and the welding residual distortion can be effectively reduced.

Funding: This work is supported by the Education Department Foundation of Liaoning Province (No. L201749) and the Natural Science Foundation of Liaoning Province (No. 20180550206).

\section{References}

[1] S.D. Ji, Z.P. Yang, Q. Wen, Y.M. Yue, and L.G. Zhang, High. Temp. Mat. Pr., 35 (2016) 375-379.

[2] H.J. Liu, H. Fujii, M. Maeda, and K. Nogi, J. Mater. Sci. Lett., 22 (2003) 1061-1063.

[3] Y.X. Huang, X.C. Meng, Y.M. Xie, L. Wang, Z.L. Lv, J. Cao, and J.C. Feng, Compos. Part. A-Appl. S., 105 (2018) 235-257.

[4] P.L. Threadgill, A.J. Leonard, H.R. Shercliff, and P.J. Withers, Metall. Rev., 54 (2009) 49-93.

[5] M.Z.H. Khandkar, J.A. Khan, A.P. Reynolds, and M.A. Sutton, J. Mater. Process. Technol., 174 (2016) 195-203.

[6] Y.C. Chen, H.J. Liu, and J.C. Feng, Mater. Sci. Eng. A., 420 (2006) 21-25.

[7] H.J. Aval, S. Serajzadeh, N.A. Sakharova, A.H. Kokabi, and A. Loureiro, J. Mater. Sci., 47 (2012) 5428-5437.

[8] S.W. Kang, B.S. Jang, and H.C. Song, J. Mech. Sci. Technol., 29 (2015) 1111-1121.

[9] D.G. Richards, P.B. Prangnell, P.J. Withers, S.W. Williams, T. Nagy, and S. Morgan, Sci. Technol. Weld. Joining., 15 (2010) 156-165.

[10] J. Altenkirch, A. Steuwer, M. Peel, D.G. Richards, and P.J. Withers, Mater. Sci. Eng. A., 488 (2008) 16-24.

[11] M. Riahi and H. Nazari, Int. J. Adv. Manuf. Technol., 55 (2010) 143-152.

[12] A. Steuwer, S. J. Barnes, J. Altenkirch, R. Johnson, and P. J. Withers, Metall. Mater. Trans. A., 43 (2012) 2356-2365.

[13] X. Huang and A.P. Reynolds, Sci. Technol. Weld. Joining., 23 (2017) 1-8.

[14] X.W. Wang, J.M. Gong, Y.P. Zhao, and Y.F. Wang, High. Temp. Mat. Pr., 34 (2015) 227-236.

[15] Y.X. Huang, L. Wan, S.X. Lv, and J.C. Feng, Sci. Technol. Weld. Joining., 18 (2013) 239-246.

[16] Y.M. Yue, Q. Wen, S.D. Ji, L. Ma, and Z. Lv, High. Temp. Mat. Pr., 36 (2016) 733-739.

[17] M.N. Avettand-Fènoël and R. Taillard, Mater. Des., 89 (2016) 348361.

[18] D.X. Li, X.Q. Yang, L. Cui, F. He, and X. Zhang, J. Mater. Process. Technol., 222 (2015) 391-398.

[19] J.Q. Li, H.J. Liu, Mater. Des., 43 (2013) 299-306.

[20] S.D. Ji, Z.W. Li, Z.L. Zhou, and L.G. Zhang, Int. J. Adv. Manuf. Technol., 90 (2016) 1-9.

[21] T.Z. Sun, M.J. Roy, D. Strong, P.J. Withers and P.B. Prangnell, J. Mater. Process. Technol., 242 (2017) 92-100.

[22] A. Simar, C. Jonckheere, K. Deplus, T. Pardoen, and B.D. Meester, Sci. Technol. Weld. Joining., 15 (2010) 254-259.

[23] S.D. Ji, L.G. Zhang, G.H. Luan, C.L. Dong, and L. Fu, J. Mater. Sci. Technol., 27 (2011) 647-652.

[24] W.Y. Li, R.R. Jiang, Z.Z. Zhang, and Y. Ma, Adv. Eng. Mater., 15 (2013), 1051-1058.

[25] S.D. Ji, X.C. Meng, J.G. Liu, L.G. Zhang, and S.S. Gao, Mater. Des., 62 (2014) 113-117.

[26] Y.B. Zhong, C.S. Wu, and G.K. Padhy, J. Mater. Process. Technol., 239 (2017) 273-283.

[27] Q.Z. Zhang, L.W. Zhang, W.W. Liu, X.G. Zhang, W.H. Zhu, and S. Qu, Sci. Technol. Weld. Joining., 11 (2006) 737-743.

[28] A.P. Reynolds, W. Tang, Z. Khandkar, J.A. Khan, and K. Lindner, Sci. Technol. Weld. Joining., 10 (2005) 190-199.

[29] Z. Feng, X.L. Wang, S. A. David, and P. S. Sklad, Sci. Technol. Weld. Joining., 12 (2013) 348-356. 
[30] M. Peel, A. Steuwer, M. Preuss, and P.J. Withers, Acta. Mater., 51 (2003) 4791-4801.

[31] H. Lombard, D.G. Hattingh, A.Steuwer, and M.N. James, Mater. Sci. Eng. A., 501 (2009) 119-124.

[32] T. Li, Q.Y. Shi, H.K. Li, W. Wang, and Z.P. Cai, Mater. Sci. Forum., 580-582 (2008) 263-266.

[33] T.Z. Sun, M.J. Roy, D. Strong, P.J. Withers, and P.B. Prangnell, J. Mater. Process. Technol., 242 (2017) 92-100.

[34] S.W. Kang, B.S. Jang, and H.C. Song, J. Mech. Sci. Technol., 29 (2015) 1111-1121.
[35] D. G. Moghadam, K. Farhangdoost, and R. M. Nejad, Metall. Mater. Trans. B., 47 (2016) 2048-2062.

[36] S.W. Wen, P.A. Colegrove, S.W. Williams, S.A. Morgan, A. Wescott, and M. Poad, Sci. Technol. Weld. Joining., 15 (2010) 440-447.

[37] N. Guo, X.Q. Yin, J. Liang, and N. Ma, Sci. Technol. Weld. Joining., 22 (2016) 1-8.

[38] Q.Y. Shi, J. Silvanus, Y. Liu, D.Y. Yan, and H.K. Li, Sci. Technol. Weld. Joining., 13 (2008) 472-478. 